\title{
Acceptance of mating by the doe rabbit and its relationships with fertility
}

\author{
A. DELAVLAU \\ I.T.A.I.I., Service technique \\ 28, we du Rocher, 75008 Paris (France)
}

An attempt was made to analyse the factors favouring the conception rate by examining both the colour of the vulva and the mode of mating.

A total of I97 matings were analysed in the first trial and 303 matings in the second one.

It was noticed that the mating acceptance rate (percentage of does effectively mated /total does presented to the male) was very high when the vulva of the females was red whereas only $5^{\circ} \mathrm{p}$. roo of the females with a pink vulva accepted mating.

It was also stated that $80 \mathrm{p}$. 100 of the females with a red vulva became pregnant. Furthermore, let us mention that matings realized with the assistance of the rabbit keeper who helds the animal while it lifts up its rump to facilitate the penetration of the male, does not seem to be an advisable method.

\section{Comparison of two reproductive rhythms in the meat rabbit First results}

\author{
P. SURDEAU, G. PERRIER, J. M. SARTORIO et I). VALENTIN \\ Chaire de production animale, E.N.I.T.A. de Dijon, \\ 21800 Quétigny (France)
}

\begin{abstract}
Lighty rabbit does from two different " hybrid "strains were distributed into 2 lonnogeneous groups and mated either immediately after kindling (" post-partum " group) or an on average Io days after kindling, ("Io days "group). The results concern the first + litters of the rabbit does, obtained according to the one or the other thythmover a period of 6 months.

The number of matings leading to conception (kindling) was not affected by the theoretical reproduction rhythm; this resulted in a shorter mean interval between kindlings for the "post partum " group (36 days versus 46.3 days). On the other hand, the number of young born (total or alive) per litter was definitely higher for the "Io days " group (8.7-7.7) than for the " post partum " group $(7 \cdot 7-6.4)$. The birth-weaning survival rates were the same for the 2 groups, as were the overall weaning-slaughter performances.

Thus, after 6 months of experimentation, the results indicate that the monthly numerical productivity was the same for the 2 groups. In the first group a larger number of litters was obtained per time unit and in the second group a larger number of young per litter.
\end{abstract}

